\title{
Stage C Chronic Lymphocytic Leukemia
}

National Cancer Institute

\section{Source}

National Cancer Institute. Stage C Chronic Lymphocytic Leukemia. NCI Thesaurus. Code C141211.

Findings: Lymphocytosis, adenopathy, and enlarged spleen and/or liver; Survival (months):

72. (from AJCC 8th Ed.) 